\title{
COMPUTATION OF THE PARAMETERS OF A SLOT- EMBEDDED CONDUCTOR USING THE FINITE ELEMENT FORMULATION OF THE IMPEDANCE BOUNDARY CONDITION
}

\author{
A.M. El-Sawy Mohamed \\ Electrical Eng. Dept., Faculty of Eng., Minia University, Egypt
}

(Received October 10, 2010 Accepted October 25, 2010)

\begin{abstract}
The finite element variational formulation of the impedance boundary condition (IBC) is applied to solve two-dimensional eddy current problems, especially at high frequencies in electrical machines. This formulation is used to compute the ac resistance and the self inductance per unit length of both a reverse ' $T$ ' slot-embedded conductors and a simple slot-embedded conductor. The proposed IBC formulation is very efficient, because it does not change the sparsity of the finite element global matrix as well as it has minimized the computing cost such as computer memory and central processing unit time. The obtained results of both the finite element method (FEM) and the IBC formulation are compared with published results.
\end{abstract}

KEYWORDS: eddy currents, FE-formulation, IBC formulation, slotembedded conductor

\section{INTRODUCTION}

The main problem when treating high frequency phenomena with the finite element method (FEM) is predominant presence of skin and proximity effects. As a solution to this problem, adaptive mesh generation has been propsed in [1]. But the use of this technique is limited only to quite low frequencies. A successful technique for handling this phenomenon then is the use of the surface impedance concept allowing the extraction from the domain of study of conducting parts [2,3]. Thus the number of nodes of the problem is reduced and the system to be solved becomes smaller.

For eddy current problems, the IBC formulation is attractive because of the elimination of the computation within the conducting medium and because of the avoidance of thin elements when the skin depth is small, such as in high frequency problems. This topic has therefore been of considerable interest to many publishers [1$16]$.

In [4], the IBC integral equation formulation was derived for solving the twodimensional (2D) eddy current problem of a conducting cylinder placed in a timeharmonic field. The surface impedance method for 2D and 3D eddy current problems was improved in [6] by using more accurate values of impedance based on the special variation of fields on the surface of conducting regions. An economic threedimensional (3-D) method using the surface impedance technique [7] was used for solving 3-D coupled electromagnetic and thermal problems. A 2-D finite element formulation of the IBC, based on the variational approach for solving eddy current problems, especially at high frequencies was developed by the author [9]. Based on this formulation, a new boundary elemental matrix (IBC matrix) representing the 
general Neumann boundary condition was developed. This formulation was very efficient, because it does not change the spasity of the finite element global matrix. In addition it has greatly reduced the computing cost such as computer memory and central processing unit time. In [11], the author has successfully applied the developed IBC formulation [9] to compute the 2D eddy current in a solid circular conductor carrying an alternating current. Moreover, the formulation has been used to compute the parameters per unit length of shielded and multiconductor power cables.

In this paper, a two-dimensional of the finite element method (FEM) and the developed FE- formulation of the impedance boundary condition (IBC) based on the variational approach are applied to compute the ac resistance and the self inductance per unit length of both a reverse ' $T$ ' slot-embedded conductors and a simple slotembedded conductor. The obtained results of the FEM are compared to published results [14]. Therefore, the obtained IBC results are compared to the results of the tested FEM.

\section{THE FIELD EQUATIONS}

In terms of the time-harmonic magnetic vector potential $\mathrm{A}$, the differential equation which governs the two-dimensional eddy current problem is given by

$$
\frac{1}{\mu}\left(\nabla^{2} A\right)=-J_{s}+j \omega \sigma A
$$

where $J_{s}$ is the unknown time harmonic source current density and $\mu, \omega$ and $\sigma$ are the permeability, angular frequency and conductivity respectively. The total current density in the conductor is given by

$$
J=J_{s}+J_{e}=J_{s}-j \omega \sigma A
$$

Where $\boldsymbol{J}_{e}$ is the eddy current density and both $\mathrm{J}_{\mathrm{s}}$ and A are unknowns and must be found. For our own problem, the boundary conditions shown in Fig. 1, are defined as :

$$
\begin{aligned}
& A=A(x, y) \text { on } \quad \mathrm{C}_{1} \\
& \frac{\partial A}{\partial n}=0 \quad \text { on } \quad \mathrm{C}_{2} \\
& \frac{\partial A}{\partial n}=-\gamma A \quad \text { on } \quad \mathrm{C}_{3}
\end{aligned}
$$

Where $\gamma$ is the propagation constant and is defined as

$$
\gamma=\sqrt{j \omega \mu \sigma}
$$

\section{THE IBC CONCEPT}

For a time- harmonic electromagnetic field incident on a conducting linear medium, the tangential components of electric field $\mathrm{E}$ and the magnetic field $\mathrm{H}$ inside the conductor and on its surface are related to each other [1], except at (or near) the corners, by

$$
n \times \bar{E}=\bar{Z}_{s} \hat{n} \times(\bar{n} \times \bar{H})
$$




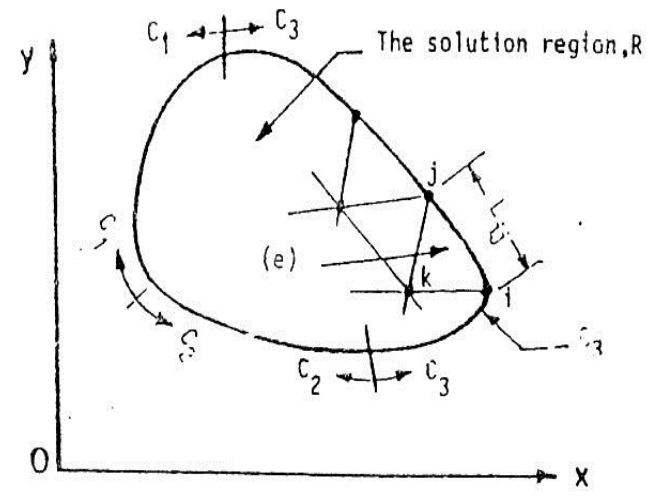

Fig. 1 solution domain for 2D eddy current problem

where $\mathrm{n}$ is the unit vector out of the conductor and a time dependent is assumed. The surface impedance, $Z_{s}$, of an infinite conducting half space plane is given by

$$
Z_{s}=\frac{1+j}{\delta \sigma}
$$

where $\delta$ is the electromagnetic penetration depth and is defined as

$$
\delta=\sqrt{\frac{2}{\omega \mu \sigma}}
$$

After rearranging Eqs. (7) through (8), we obtain an equation similar to Eq. (5). This means that the IBC approximation takes the same form of the general Neumann boundary condition.

\section{THE FE-IBC FORMULATIONS}

\subsection{The Fe-Variational Formulation}

The formulation and solution of eddy current problems has been traditionally regarded as one of the more difficult areas of electromagnetic. Using the integro-differential approach [14], both the magnetic vector potential (m.v.p.) A and the source current density $\mathbf{J}_{\mathrm{s}}$ are treated as unknowns and the classical diffusion Eq. (1) is complemented with Eq. (2)

$$
I=I_{s}+I_{e}=\iint J_{s} d s-j \omega \sigma \iint A d s
$$

where $I, I_{s}$, and $I_{e}$ are the total current, the total source current and the total eddy current respectively. Hence $\mathrm{J}_{\mathrm{s}}$ can be expressed as

$$
J_{s}=\frac{I}{a}+\frac{j \omega \sigma}{a} \iint A d s
$$

Substituting Eq. (11) into Eq. (1), we can obtain

$$
\frac{1}{\mu}\left(\nabla^{2} A\right)-j \omega \sigma A+j \omega \frac{\sigma}{a} \iint A d s=-\frac{I}{a}
$$


The only unknown in Eq. (12) is magnetic vector potential (m.v.p.) A. It can be shown that the m.v.p., A that satisfies Eqs. (2), (3) and (12), also minimizes the functional $\mathrm{F}(\mathrm{A})$ as

$$
\begin{aligned}
F(A) & =\iint_{R}\left[\frac{1}{\mu}\left\{\left(\frac{\partial A}{\partial x}\right)^{2}+\left(\frac{\partial A}{\partial y}\right)^{2}\right\}\right. \\
& \left.+j \frac{\omega \sigma}{2} A^{2}-\left(\frac{I}{a}+\frac{j \omega \sigma}{a} \iint A d s\right) A\right] d x d y
\end{aligned}
$$

The variational principle on which we can base the derivation of the elemental equations is

$$
\left(\frac{\partial F}{\partial A_{m}}\right)_{m=i, j, k}=0
$$

The solution region $\mathrm{R}$, is shown in Fig. 1, is subdivided into triangular elements. After minimization of the functional $\mathrm{F}(\mathrm{A})$ (Eq.13), we can finally obtain the following set elemental matrix as

$$
[S]^{(e)}[A]^{(e)}+[T]^{(e)}[A]^{(e)}-\left[T_{D}\right]^{(e)}[C]^{(e)}[A]^{e}=[I]^{(e)}
$$

where the elemental matrices $[\mathrm{S}]^{(\mathrm{e})},[\mathrm{T}]^{(\mathrm{e})}$ and $[\mathrm{I}]^{(\mathrm{e})}$ are given in the Appendix. The elemental matrix $[\mathrm{C}]^{(\mathrm{e})}$ consists of identical rows made up of Newton-cotes quadrature weight [18]. The elemental matrix $\left[\mathrm{T}_{\mathrm{D}}\right]^{(\mathrm{e})}$ is obtained in [11] and is given in the Appendix. By extending Eq. (15) to each of the triangular subdivisions shown in Fig. 1 , the final global matrix equations are obtained in the form

$$
[S][A]+[T][A]-\left[T_{D}\right][C][A]=[I]
$$

\subsection{The Ibc Formulation}

It can be shown that the m.v.p., A that satisfies Eqs. (2) through (4) and Eq. (12), also minimizes the functional $\mathrm{F}(\mathrm{A})$ as

$$
\begin{aligned}
F(A)= & \iint_{R}\left[\frac{1}{\mu}\left\{\left(\frac{\partial A}{\partial x}\right)^{2}+\left(\frac{\partial A}{\partial y}\right)^{2}\right\}\right. \\
& \left.+j \frac{\omega \sigma}{2} A^{2}-J_{s} A\right] d x d y \\
& +\int_{R} \frac{1}{2} \gamma A^{2} d C_{3}
\end{aligned}
$$

Substituting from Eq. (12) by the current density $\mathbf{J}_{\mathrm{s}}$ into Eq. (17), we obtain

$$
\begin{aligned}
F(A) & =\iint_{R}\left[\frac{1}{\mu}\left\{\left(\frac{1}{\mu} \frac{\partial A}{\partial x}\right)^{2}+\left(\frac{\partial A}{\partial y}\right)^{2}\right\}\right. \\
& \left.+\frac{j \omega \sigma}{2} A^{2}-\left(\frac{I}{a}+\frac{j \omega \sigma}{a} \iint A d s\right) A\right] d x d y \\
& +\int_{R} \frac{1}{2} \gamma A^{2} d C_{3}
\end{aligned}
$$


The variational principle on which we can base the derivation of the elemental equations is

$$
\left(\frac{\partial F}{\partial A_{m}}\right)_{m=i, j, k}=0
$$

After minimization, the functional F(A) (Eq. 18), the following set of the elemental equations can be finally obtained as :

$$
[S]^{(e)}[A]^{(e)}+[T]^{(e)}[A]^{(e)}-\left[T_{D}\right]^{(e)}[C]^{(e)}[A]^{e}+\left[T_{B}\right]^{(e)}[A]^{(e)}=[I]^{(e)}
$$

The matrix $\left[T_{B}\right]^{(e)}$ is the IBC matrix which is obtained by the author [9] as

$$
\left[T_{B}\right]=l_{i j} \gamma\left[\begin{array}{ccc}
\frac{1}{3} & \frac{1}{6} & 0 \\
\frac{1}{6} & \frac{1}{3} & 0 \\
0 & 0 & 0
\end{array}\right]
$$

Where $l_{i j}$ is the boundary segment length as shown in Fig. 1. By extending Eq. (20) to each of the triangular subdivisions shown in Fig. 1, the final global matrix equations are obtained in the form

$$
[S][A]+[T][A]-\left[T_{D}\right][C][A]+\left[T_{B}\right][A]=[I]
$$

\section{PARAMETERS COMPUTATION}

The electrical parameters, i.e. the ac resistance and the self inductance per unit length for slot-embedded conductors can be obtained using the following methods:

\subsection{The Energy Method}

The energy-related quantities such as loss density and stored magnetic energy are used to compute the ac resistance and the self inductance per unit length. The loss density for a conductor is given by the function $\mathrm{u}(\mathrm{x}, \mathrm{y})$ as

$$
u(x, y)=\frac{|J(x, y)|^{2}}{\sigma}
$$

where the total current density may be obtained as

$$
J(x, y)=J_{s}+J_{e}(x, y)=\frac{I_{s}}{a}-j \omega A(x, y)
$$

The total losses per unit length are obtained as

$$
U=\iint u(x, y) d x d y
$$

The ac-dc loss ratio can be computed as

$$
\text { ac }- \text { dcloss ratio }=\frac{U}{U_{d c}}
$$

where the dc losses per unit length of the conductor are given by 
$U_{d c}=|\boldsymbol{I}|^{2} R_{d c}=\frac{|\boldsymbol{I}|^{2}}{\sigma a}$

where $\mathrm{a}$ is the conductor area. The ac losses per unit length of the conductor are given by

$$
U=|\boldsymbol{I}|^{2} \boldsymbol{R}
$$

Where $\mathrm{R}$ is the ac resistance per unit length. The self inductance of a conductor per unit length can be obtained from

$$
\boldsymbol{W}=\frac{1}{2} \boldsymbol{L}|\boldsymbol{I}|^{2}
$$

where $\mathrm{W}$ is the magnetic stored energy which it can be obtained per unit length of a conductor as

$$
W=\operatorname{Re}\left[\frac{1}{2} \iint A(x, y)-J_{s}^{*}(x, y) d x d y\right]
$$

Using Eqns. (24), (29) and (30), the self inductance per unit length can be obtained as

$$
L=\frac{1}{|I|^{2}} \operatorname{Re}\left[J_{s}^{*} \iint A(x, y) d x d y\right]
$$

\subsection{The Voltage Drop}

The source current density for each conductor can be obtained as

$$
J_{s}=\frac{I_{s}}{a}
$$

where $\mathrm{a}$ is the cross-sectional area of the conductor, and the current density $\mathrm{J}_{\mathrm{s}}$ is obtained from Eq. (1). The voltage drop per unit length of the conductor is obtained as

$$
\boldsymbol{V}=\frac{\boldsymbol{J}_{s}}{\sigma}
$$

The impedance per unit length of the conductor can be computed as

$$
Z=\frac{V}{I}
$$

The real part of $\mathrm{Z}$ is the ac resistance per unit length and the imaginary part is the reactance per unit length

\section{NUMERICAL RESULTS}

In this paper, both the FE-formulation and the IBC formulation are applied to compute the electrical parameters, i.e. the ac resistanc and the self inductance per unit length for both a reverse ' $\mathrm{T}$ ' slot-embedded conductor and a simple slot-embedded conductor.

\subsection{THE REVERSE 'T’ SLOT-EMBEDDED CONDUCTOR}

In this paper, the results of the ac resistance in a reverse ' $\mathrm{T}$ ' slot-embedded conductor is computed using the developed FE program based on the FE-variational formulation 
and is tested by the published results [14]. The FE formulation gives accurate results specially at low frequencies. Then, the results of the present IBC formulation for this model are compared to the results of the tested FE-formulation. This FE-model is discretized into 216 triangular elements and 135 nodes and the boundary conditions (Eqs. (3) and (4)) are also considered as shown in Fig. 2. The FE program solved 128 m.v.p. unknowns for this model. The obtained results of the ratio $R_{A C} / R_{D C}$ are plotted against Dwight's parameter D, and compared to the published results [14]. These results are found to be in good agreement with the published results as shown in Fig. 3.

Therefore, the present results of the IBC model are compared to the results of the tested FE-program based on the FE-variational formulation. The IBC model shown in Fig. 4 is discretized into 100 triangular elements and 87 nodes and the boundary conditions (Eqs. (3) - (5)) are also considerd as shown in Fig.4..The discretization of this model is limited to only one layer inside the conductor besides layers that represent the free space external region. The developed IBC computer program solved 49 m.v.p. unknowns for this model. The results of the ac resistance, $\mathrm{R}$ and the self inductance $\mathrm{L}$ per meter which are obtained using the developed IBC formulation were found to be in good agreement with the FE results especially at high frequencies as shown in Table 1 and Table 2. A comparison of computational requirements for the present IBC formulation and the FE-formulation are shown in Table 3. The obtained results are carried out with the total current I equal to $1 \mathrm{~A}$.

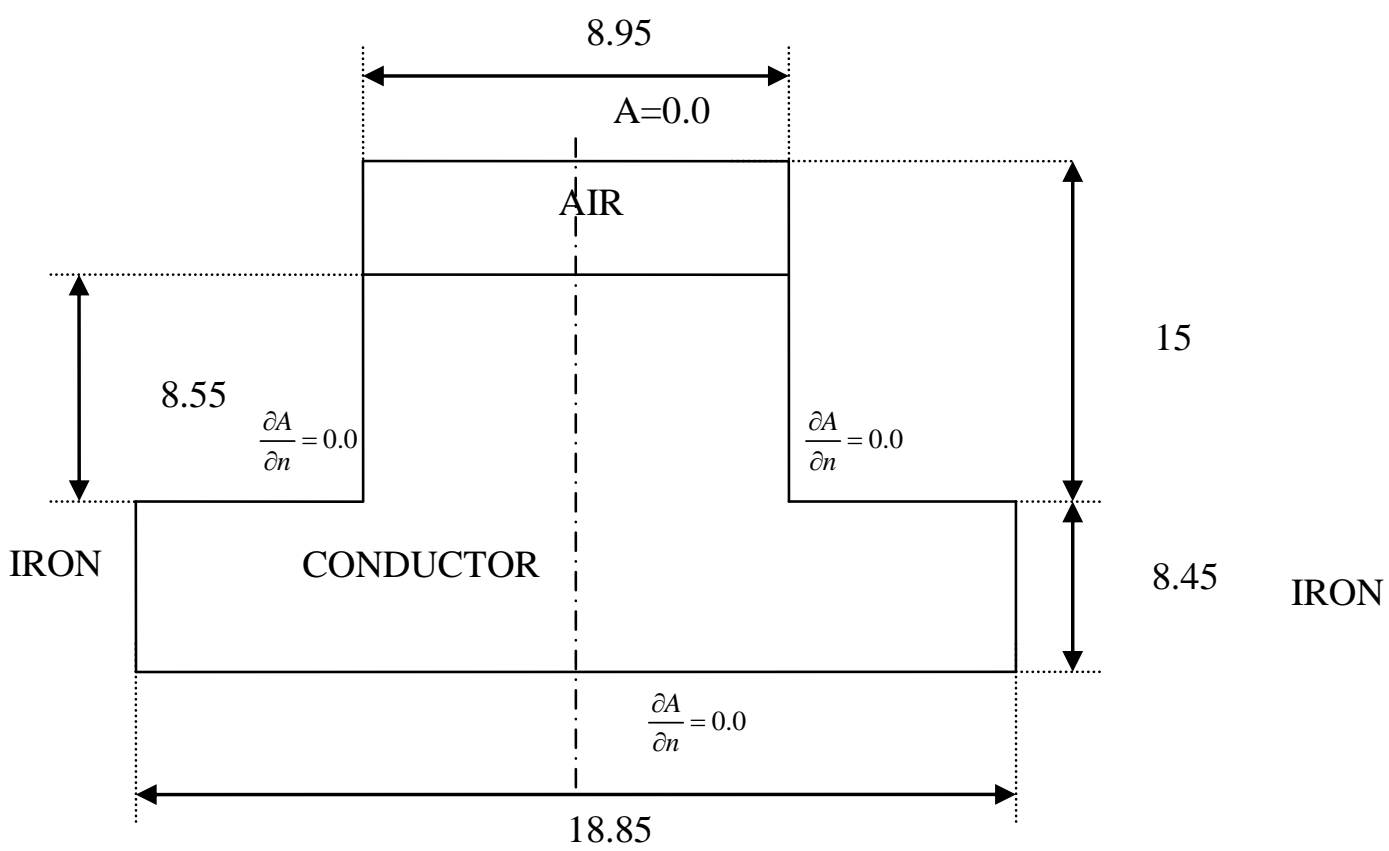

Fig. 2. Reverse 'T' Slot-embedded conductor (FEM model) (geometry and dimensions are in millimeters) 


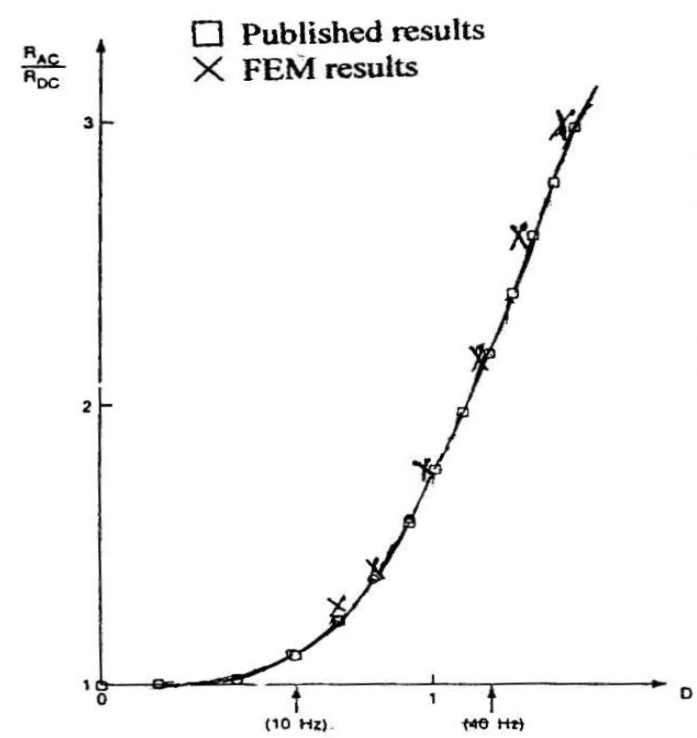

Fig. 3 AC-DC resistance ratio versus Dwight's parameter $\mathrm{D}$ for reverse ' $\mathrm{T}$ ' Slotembedded conductor. $\left(\mathrm{R}_{\mathrm{DC}}=0.731108 \times 10^{-4} \Omega / \mathrm{m}, D=\sqrt{\frac{2 \mu f}{R_{D C}}}\right)$

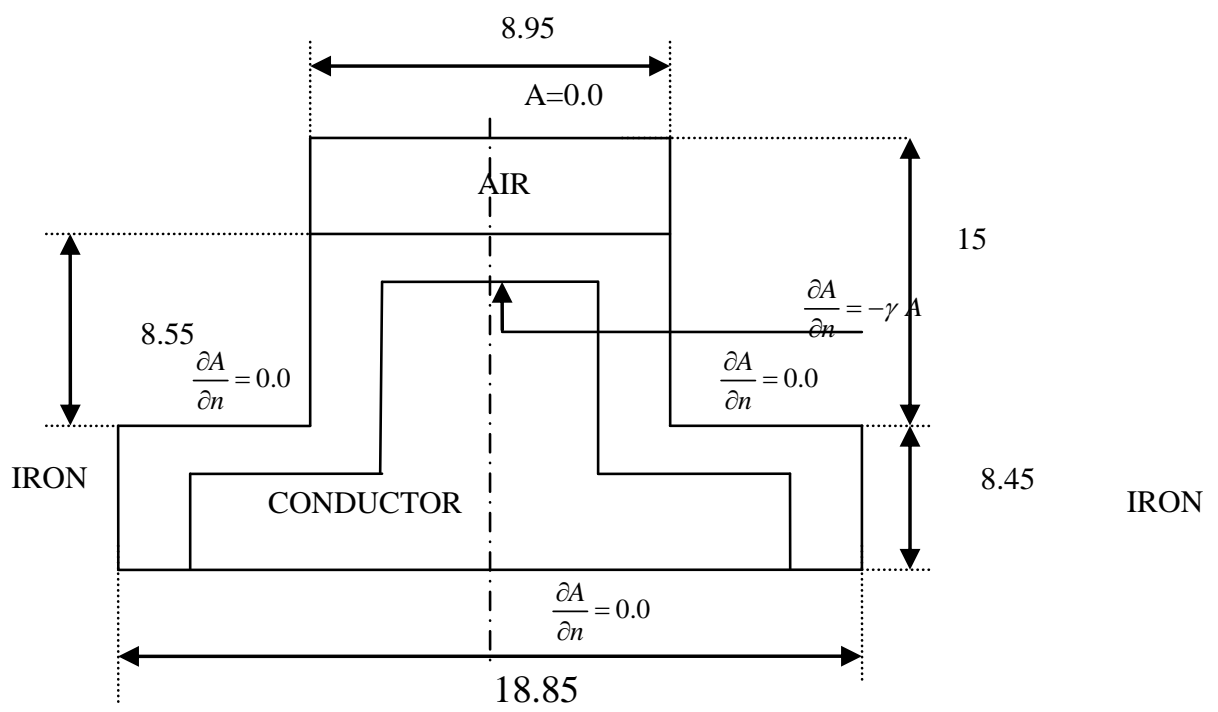

Fig. 4. Reverse 'T' Slot-embedded conductor (IBC model) (geometry and dimensions are in millimeters)

Table 1 Results of $R(\Omega / m)$ for the reverse ' $T$ ' slot-embedded conductor

\begin{tabular}{|c|c|c|c|c|}
\hline $\mathrm{f}(\mathrm{c} / \mathrm{s})$ & 60 & 100 & 200 & 300 \\
\hline $\mathrm{FEM}$ & $1.78 \times 10^{-4}$ & $1.8 \times 10^{-4}$ & $1.81 \times 10^{-4}$ & $2.414 \times 10^{-4}$ \\
\hline Present IBC & $1.95 \times 10^{-4}$ & $1.98 \times 10^{-4}$ & $2.11 \times 10^{-4}$ & $2.32 \times 10^{-4}$ \\
\hline
\end{tabular}


Table 2 Results of $\mathrm{L}(\mathrm{H} / \mathrm{m})$ for the reverse ' $\mathrm{T}$ ' slot-embedded conductor

\begin{tabular}{|c|c|c|c|c|}
\hline $\mathrm{f}(\mathrm{c} / \mathrm{s})$ & 60 & 100 & 200 & 300 \\
\hline FEM & $3.16 \times 10^{-8}$ & $1.28 \times 10^{-8}$ & $3.82 \times 10^{-9}$ & $3.09 \times 10^{-9}$ \\
\hline Present IBC & $2.5 \times 10^{-8}$ & $1.53 \times 10^{-8}$ & $3.25 \times 10^{-9}$ & $2.91 \times 10^{-9}$ \\
\hline
\end{tabular}

Table 3 Computational requirements for the present IBC formulation for the reverse ' $T$ ' slot-embedded conductor

\begin{tabular}{|c|c|c|c|}
\hline & No. of elements & No. of nodes & No. of unknouns \\
\hline FEM & 216 & 135 & 128 \\
\hline Present IBC & 100 & 87 & 49 \\
\hline
\end{tabular}

\subsection{A Simple Slot-Embedded Conductor}

The FEM model is discretized into 180 triangular elements and 112 nodes and the boundary conditions (Eqns. (3) and (4)) are also considered as shown in Fig.5a. The FE program solved 105 m.v.p. unknowns for this model. The present IBC results for the IBC model shown in Fig. 5b are compared to the results of the tested FE-program based on the FE-formulation.

The IBC model shown in Fig. 5b is discretized into 104 triangular elements and 86 nodes and the boundary conditions (Eqs (3) -(5)) are also considered (Fig.5b).The discretization of this model is limited to only one layer inside the conductor besides layers that represent the free space external region. The developed IBC computer program solved 52 m.v.p. unknowns for this model. The results of the resistance, $\mathrm{R}$ and the self inductance $\mathrm{L}$ per meter which are obtained using the developed IBC formulation were found to be in close agreement with the FE results especially at high frequencies as shown in Table 4 and Table 5. A comparison of computational requirements for the present IBC formulation and the FE-formulation are shown in Table 6. The obtained results are carried out with the total current I equal to $1 \mathrm{~A}$.

Table 4 Results of $R(\Omega / \mathrm{m})$ for a simple slot-embedded conductor

\begin{tabular}{|c|c|c|c|c|}
\hline $\mathrm{f}(\mathrm{c} / \mathrm{s})$ & 60 & 100 & 200 & 300 \\
\hline FEM & $2.34 \times 10^{-4}$ & $2.4 \times 10^{-4}$ & $2.46 \times 10^{-4}$ & $2.486 \times 10^{-4}$ \\
\hline Present IBC & $2.53 \times 10^{-4}$ & $2.63 \times 10^{-4}$ & $2.71 \times 10^{-4}$ & $2.82 \times 10^{-4}$ \\
\hline
\end{tabular}

Table 5 Results of $\mathrm{L}(\mathrm{H} / \mathrm{m})$ for a simple slot-embedded conductor

\begin{tabular}{|c|c|c|c|c|}
\hline $\mathrm{f}(\mathrm{c} / \mathrm{s})$ & 60 & 100 & 200 & 300 \\
\hline FEM & $7.48 \times 10^{-8}$ & $3.41 \times 10^{-8}$ & $1.21 \times 10^{-8}$ & $6.536 \times 10^{-9}$ \\
\hline Present IBC & $7.92 \times 10^{-8}$ & $3.77 \times 10^{-8}$ & $1.83 \times 10^{-8}$ & $6.21 \times 10^{-9}$ \\
\hline
\end{tabular}

Table 6 Computational requirements for the present IBC formulation for a simple slot-embedded conductor

\begin{tabular}{|c|c|c|c|}
\hline & No. of elements & No. of nodes & No. of unknouns \\
\hline FEM & 180 & 112 & 105 \\
\hline Present IBC & 104 & 86 & 52 \\
\hline
\end{tabular}




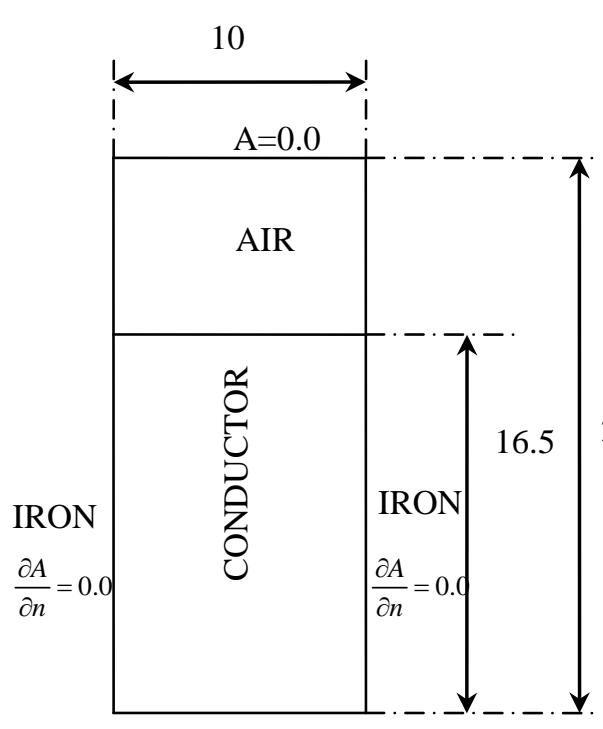

$\mathrm{a}$ - The FEM model

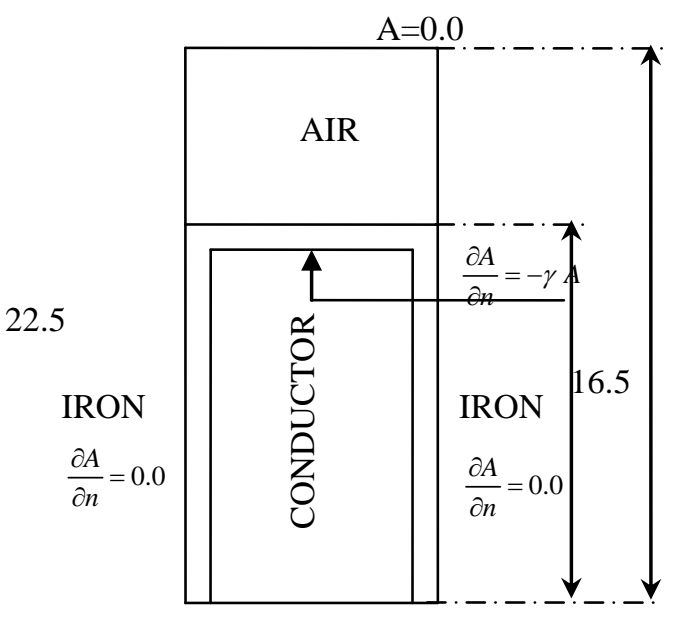

b - The IBC model

Fig. 5 Simple slot-embedded conductor

(geometry and dimensions are in millimeters)

\section{CONCLUSIONS}

The present work proposes an application of the finite element variational formulation of the impedance boundary condition (IBC) for solving two-dimensional eddy current problems, especially at high frequencies in electrical machines. Both the finite element method (FEM) and the IBC formulation are used to compute the ac resistance and the self inductance per unit length of both a reverse ' $\mathrm{T}$ ' slot-embedded conductors and a simple slot-embedded conductor. The main advantage of this IBC formulation is that the FE-global matrix is still banded and symmetric. Moreover, this formulation has greatly reduced the number of unknowns of the problem. So, the formulation has minimized the computing cost such as computer memory and central processing unit time, since it has greatly reduced the number of nodes and the number of unknowns of the problem. The obtained results of both the finite element method (FEM) and IBC formulation are compared to published results.

\section{REFERENCES}

1. Darcherif, A., Raizer, A., Imhoff, J.E, Meunier, G., and Sabonnadiere, J.C.: 'New teqniques in finite elements method applied in power cable characteristics calculation', IEEE Trans. On Magn., Vol. 26, pp. 2338-2340, Sept. 1990.

2. Schelkunoff, S.A. 'The electromagnetic theory of coaxial transmission lines and cylindrical shields', BST Journal, Vol. 13, pp. 552-579, 1934. 
3. Subramaniam, S., and Hoole, S.R.H. :'The impedance boundary condition in the boundary element vector potential formulation', IEEE Trans. On Magn., Vol. 24, pp. 2503-2505, Nov. 1988.

4. Chuan Lu and Balasubramaniam Shanker, "Generalized Finite Element Method for Vector Electromagnetic Problems", IEEE transactions on antennas and propagation, vol. 55, no. 5, MAY 2007.

5. Fawzi, T.F., Burke, P.E, and Ahmed, M.T : 'Application of the BEM and surface impedance method for the computation of the high frequency TM-eddy current losses in conductors with edges', IEEE Trans. On Magn., Vol. 20(5), pp.22010-2112, 1984.

6. Deely, E.M., and Xiang, J. :'Improved surface impedance methods for 2-D and 3-D problems', IEEE Trans. On Magn., Vol. 24(1), pp. 209-211, 1988.

7. Sturgess, J.P., and Preston, T.W. : “An economic solution for 3-Dcoupled electromagnetican thermal eddy current problems", IEEE Trans. On Magn., Vol. 28(2), pp. 1267-1270, 1992.

8. H. Bulent Ertan, Kemal Leblebicioglu, Bulent Avenoglu and Murat Pirgaip, "High-Frequency Loss Calculation in a Smooth Rotor Induction Motor Using FEM", IEEE Trans. on Energy Conver., VOl. 22, NO. 3, Sept. 2007.

9. El-Sawy Mohamed, A.M. : "Finite Element variational formulation of the impedance boundary condition for solving eddy current problems", IEE Proceeding, Vol. 142, No. 4, pp. 293-298, July 1995.

10. Holland, S.A, O’Connell, G.P., and Haydock, L.: "Calculating stray losses in power transformers using surface impedance with finite elements", IEEE Trans. On Magn., (28), Vol. 2, pp.1355-1358, 1992.

11. El-Sawy Mohamed, A.M.: "On the use of finite element formulation of the impedance boundary condition in shielded and multiconductor power cables" Bulletin of the Faculty of Engineering, Assiut University, VOl. 25, No. 1, January 1997.

12. Yacine Amara, Jiabin Wang and David Howe, "Analytical Prediction of EddyCurrent Loss in Modular Tubular Permanent-Magnet Machines", IEEE Trans. on Energy Conversion, Vol. 20, No. 4, Dec. 2005.

13. Rong-Jie Wang and Maarten J. Kamper, "Calculation of Eddy Current Loss in Axial Field Permanent-Magnet Machine With Coreless Stator", IEEE Trans. On energy conver., Vol. 19, No. 3, Sept. 2004.

14. Konad, A.:L " The numerical solution of steady state skin effect problems- An integrodifferintial approach", IEEE Trans. On MAGN. Vol-MAG 17, No. 1 pp.1148-1152, 1981.

15. Chari, M.V.K.: "The Finite element solution of the eddy current problem in magnetic structures", IEEE Trans. on Power Appar. and Syst., PAS-93, No. 1, pp 62-69, 1973.

16. Lammerraner, J. and Stafl, M.: "Eddy currents", ILIFE BOOKS LTD., London, 1964.

17. Felliziani, M.: "Characteristic impedance boundary conditions for the solution of open boundary problems “, IEEE Trans. On Magn., Vol. 29, No. 2, pp. 1816-1819, 1993.

18. Silverster, P.: "Symmetric quadrature formulae for simplexes", Math. Comp., Vol. 24, No. 109, pp.95-100, 1970. 


\section{Appendix}

The previously published elemental matrices $[\mathrm{S}]^{(\mathrm{e})},[\mathrm{T}]^{(\mathrm{e})},[\mathrm{I}]^{(\mathrm{e})}$ are given in $[15]$ as $[S]^{e)}=\frac{1}{4 \mu \Delta}\left[\begin{array}{lll}\left(b_{i} b_{i}+d_{i} d_{i}\right) & \left(b_{i} b_{j}+d_{i} d_{j}\right) & \left(b_{i} b_{k}+d_{i} d_{k}\right) \\ \left(b_{j} b_{i}+d_{j} d_{i}\right) & \left(b_{j} b_{j}+d_{j} d_{j}\right) & \left(b_{j} b_{k}+d_{j} d_{k}\right) \\ \left(b_{k} b_{i}+d_{k} d_{i}\right) & \left(b_{k} b_{j}+d_{k} d_{j}\right) & \left(b_{k} b_{k}+d_{k} d_{k}\right)\end{array}\right]$

Where

$$
b_{i}=\left(y_{j}-y_{k}\right), d_{i}=\left(x_{k}-x_{j}\right)
$$

and so on. where $\Delta$ is the area of the triangular element, (e) shown in Fig. 1, the remaining constants of matrix $[\mathrm{S}]^{(\mathrm{e})}$ are given in [15]. The remaining matrices are given as :

$$
[T]^{(e)}=\frac{j \omega \sigma \Delta}{12}\left[\begin{array}{lll}
2 & 1 & 1 \\
1 & 2 & 1 \\
1 & 1 & 2
\end{array}\right]
$$

and

$$
[I]^{(e)}=\frac{J \Delta}{3}\left[\begin{array}{l}
1 \\
1 \\
1
\end{array}\right]
$$

The elemental matrix $\left[T_{D}\right]$ is given in [11], where $a$ is the conductor area.

\section{حساب عناصر الموصلات المغموسة في مجرة الآلات الكهربية باستخدام طريقة العناصر المحدودة مع الممانعة الحدودية أحمد محمد الصاوي محمد

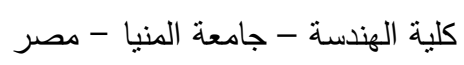

ملخص - يعرض البحث نطبيقا لطريقة العناصر المحدودة في بعدين و ذللك بتمثيل الممانعة الحدودية ( IBC )

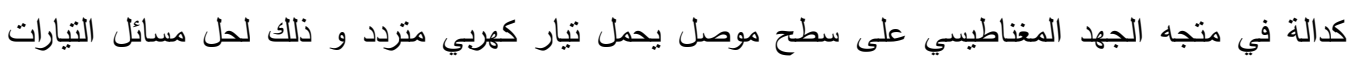

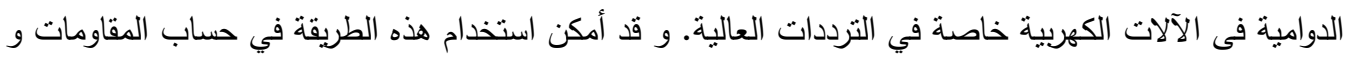

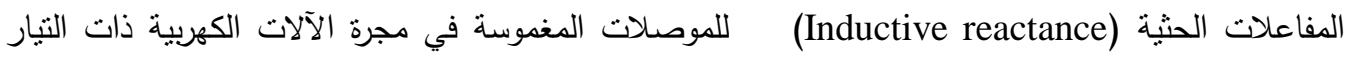

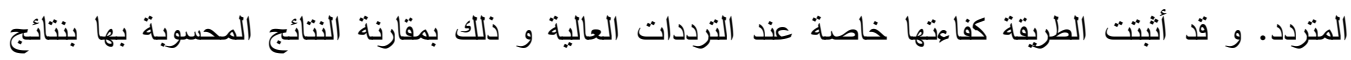

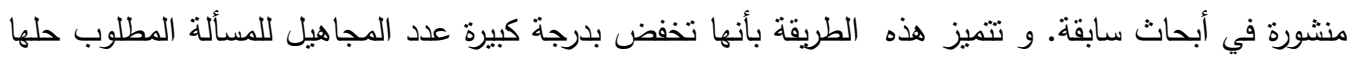

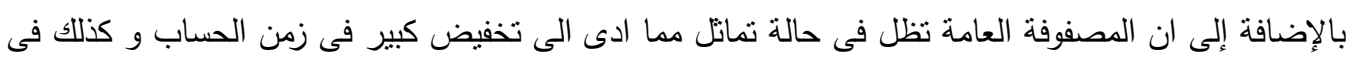

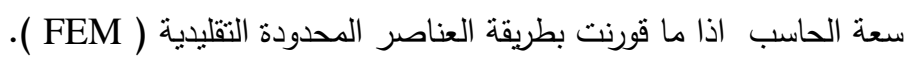

